\title{
Estudio comparativo de tres aditivos zootécnicos en el comportamiento productivo y sanitario de cerdos en el período post-destete
}

\section{Comparative study of three zootechnical additives on the production and sanitary behavior of pigs in the post-weaning stage}

Fecha de recepción: 4 de enero de 2016 Fecha de aceptación: 23 de mayo de 2016
Luis Gerardo Flores-Mancheno ${ }^{1}$

Yaneisy García-Hernández ${ }^{2}$

Julio Enrique Usca-Méndez ${ }^{3}$

William Orlando Caicedo-Quinche ${ }^{4}$

\section{Resumen}

El objetivo del trabajo fue comparar el efecto de tres aditivos (dos probióticos y un antibiótico) en el comportamiento productivo y la salud de cerdos en el período post- destete. Para esto se utilizaron 120 cerdos castrados, del cruce Landrace x Large White con padre Blanco Belga x Pietrain, de 28 d de edad y $6,87 \mathrm{~kg}$, distribuidos en tres grupos experimentales según diseño completamente aleatorizado con cuatro repeticiones cada uno. Los tratamientos (T) evaluados fueron: $1 \mathrm{~kg}$ de virginiamicina al $2 \%$ por tonelada de alimento (T1), 1 kg de probiótico con Saccharomyces cerevisiae, Bacillus subtilis y enzimas digestivas por tonelada de alimento (T2) y $15 \mathrm{~mL}$ de preparado ecuatoriano con bacterias lácticas, levaduras y enzimas por kg de peso vivo (PV) de los animales (T3). En este último grupo fue donde se obtuvo el mayor peso vivo final $(25,85 \mathrm{~kg}, \mathrm{P}<0.0001)$ y la mejor ganancia de peso total $(18,97 \mathrm{~kg}, \mathrm{P}<0.0001)$ y diaria $(451,75 \mathrm{~g} / \mathrm{d}, \mathrm{P}<0.0001)$. También, para el mismo grupo se encontraron las conversiones de materia seca, proteína bruta y energía metabolizable más eficientes (1,52 kg/kg de PV; 381,57 g/kg de PV y 22,99 MJ/ $\mathrm{kg}$ de PV, respectivamente). El porcentaje de animales con diarreas difirió $(\mathrm{P}<0,0001)$ entre el grupo que recibió la virginiamicina $(50,61 \%)$ y los aditivos microbianos $(27,98 \%$ y $21,39 \%)$, sin diferencias entre estos últimos. Se concluye que los aditivos microbianos mejoran el comportamiento productivo y sanitario de cerdos en post-destete con respecto a la virginiamicina, y este efecto fue mayor con el preparado microbiano ecuatoriano.

1 Ph.D. Escuela Superior Politécnica de Chimborazo (Riobamba, Ecuador). Iflores@espoch.edu.ec

2 Ph.D. Instituto de Ciencia Animal (Mayabeque, Cuba). yaneisyg@ica.co.cu

3 MSc. Escuela Superior Politécnica de Chimborazo (Riobamba, Ecuador). juscamendez@yahoo.es

4 Ph.D. Universidad Estatal Amazónica (Pastaza, Ecuador). cienciasdelatierra@uea.edu.ec 
Palabras clave: aditivos alimentarios; animales con diarreas; probiótico; virginiamicina.

\begin{abstract}
The objective of the study was to compare the effect of three additives (two probiotics and antibiotic) on productive performance and health of pigs in the post-weaning period. For this 120 barrows of the crossing Landrace $x$ Large White with father Belgian White $x$ Petrain were used, they were of 28 days of age and $6.87 \mathrm{~kg}$, divided into three experimental groups based on a completely randomized design and each one with four replications The treatments $(\mathrm{T})$ evaluated were: $1 \mathrm{~kg}$ of virginiamycin at $2 \%$ per ton of feeding (T1), $1 \mathrm{~kg}$ of probiotic with Saccharomyces cerevisiae, Bacillus subtilis and digestive enzymes per ton of feeding (T2) and $15 \mathrm{~mL}$ of Ecuadorian preparation with lactic acid bacteria, yeasts and enzymes per $\mathrm{kg}$ of body weight (BW) of animals (T3). In this last group it was where the highest final bodyweight was obtained $(25.85 \mathrm{~kg}, \mathrm{P}<0.0001)$ and the best total weight gain $(18.97 \mathrm{~kg}, \mathrm{P}<0.0001)$ and daily (451.75 g /d , P <0.0001). Also, for the same group the conversions of dry matter, crude protein and metabolizable energy were found to be more efficient $(1.52 \mathrm{~kg} / \mathrm{kg}$ of BW; $381.57 \mathrm{~g} / \mathrm{kg}$ of PV and 22.99 $\mathrm{MJ} / \mathrm{kg}$ of BW, respectively). The percentage of animals with diarrhea differed $(\mathrm{P}<0.0001)$ between the group that received virginiamycin $(50.61 \%)$ and microbial additives $(27.98 \%$ and $21.39 \%)$, with no differences between these last two. It is concluded that microbial additives improve the productive and sanitary performance of post -weaning pigs with regards to virginiamycin, and this effect was greater with the Ecuadorian microbial preparation.
\end{abstract}

Keywords: animals with diarrhea; food additives; probiotic; virginiamycin. 


\section{Introducción}

El incremento de la eficiencia en los sistemas intensivos y semi-intensivos de producción porcina se puede lograr cuando se emplean aditivos alimentarios (1). El uso de estos productos puede mejorar los procesos metabólicos y digestivos, así como modular la respuesta inmune de los animales. Efectos que inciden en el control, de forma preventiva, de patologías digestivas y respiratorias y en el aumento de los rendimientos productivos.

Durante décadas, dentro de los aditivos promotores del crecimiento animal se aplicaron los antibióticos, en dosis bajas y de forma masiva (2). Sin embargo, su uso prolongado e indiscriminado creó problemas de resistencia microbiana y agudizó la aparición de efectos residuales en los alimentos para el consumo humano (3). Además, el uso de estos antimicrobianos puede provocar desequilibrio en el ecosistema microbiano gastrointestinal y predisponer a los animales a contraer enfermedades. Por eso, a nivel internacional, varias jurisdicciones restringieron o prohibieron el uso de los antibióticos promotores del crecimiento animal (4, $5)$.

Ante la problemática anterior, la comunidad científica prestó mayor interés a los estudios de evaluación e introducción en las prácticas de alimentación y manejo animal de otros aditivos zootécnicos, como los probióticos, que contribuyeran a evitar los efectos negativos del uso de antibióticos. Los probióticos, formados por microorganismos vivos, afectan beneficiosamente la salud intestinal de los animales, contribuyen a establecer el equilibrio microbiano de su tracto gastrointestinal, pueden mejorar los procesos digestivos y absortivos, modular la respuesta inmune y, consecuentemente, mejorar el comportamiento productivo (6, 7).

En los sistemas productivos de Ecuador no se emplean ampliamente los probióticos. Apenas, en los últimos cinco años, comienzan a encontrarse trabajos investigativos donde se evidencian las ventajas del uso de estos productos $(8,9)$. En este sentido, Díaz et al. (10) informaron la obtención de un preparado microbiano nativo, a partir de suero fresco de leche, con alta concentración de bacterias lácticas y levaduras, además de contener ácidos orgánicos y enzimas. Posteriormente, este preparado fue evaluado, a razón de $15 \mathrm{~mL} / \mathrm{kg}$ de peso vivo, en la dieta de cerdos en el período de post-destete con efecto benéfico en su respuesta productiva y sanitaria (11). Sin embargo, se conoce que la efectividad de los aditivos microbianos depende de factores como las especies o cepas que constituyan el principio activo $(12,13)$, lo que a su vez contribuye a que exista una mayor diversidad de productos. De ahí que el objetivo de la presente investigación fue comparar el efecto de tres aditivos (dos probióticos y un antibiótico) en el comportamiento productivo y sanitario de cerdos en el período de post-destete.

\section{Materiales y métodos}

Localización del experimento. El experimento se desarrolló en la Unidad Académica Porcina de la Facultad de Ciencias Pecuarias (FCP) de la Escuela Superior Politécnica de Chimborazo (ESPOCH), Ecuador.

Procedimiento experimental. Se utilizaron 120 cerdos castrados, cruce Landrace-Large White $x$ Belga-Pietrain, de $28 \mathrm{~d}$ de edad y $6,87 \mathrm{~kg}$ de peso vivo (PV). Cada unidad experimental se compuso de 10 cerdos alojados en corrales colectivos de $2 \mathrm{x}$ $2,25 \mathrm{~m}$ y piso de cemento, con densidad de un cerdo por $0,45 \mathrm{~m}^{2}$. Los animales se distribuyeron en tres grupos experimentales, bajo un diseño completamente aleatorizado. El alimento balanceado se ofreció dos veces por día, a las 8:00 am y 4:00 pm. El consumo de alimento se detalla en la Tabla I. El agua se suministró ad libitum en bebederos tipo tetina. 
Tabla I. Consumo de alimento promedio en la etapa post-destete.

\begin{tabular}{|c|c|c|}
\hline $\begin{array}{c}\text { Edad de los } \\
\text { animales (días) }\end{array}$ & $\begin{array}{c}\text { Consumo } \\
\text { promedio (kg/ } \\
\text { día) }\end{array}$ & $\begin{array}{c}\text { Consumo } \\
\text { semanal (kg) }\end{array}$ \\
\hline $28-34$ & 0,38 & 2,66 \\
\hline $35-41$ & 0,55 & 3,85 \\
\hline $42-48$ & 0,70 & 4,90 \\
\hline $49-55$ & 0,85 & 5,95 \\
\hline $56-62$ & 0,99 & 6,90 \\
\hline $63-69$ & 1,12 & 7,85 \\
\hline $\begin{array}{c}\text { Consumo total } \\
\text { de la etapa }\end{array}$ & & $\mathbf{3 2 , 1 1}$ \\
\hline
\end{tabular}

Los tratamientos $(\mathrm{T})$ evaluados fueron:

T1: concentrado + antibiótico promotor de crecimiento (virginiamicina al $2 \%, 1 \mathrm{~kg} / \mathrm{t}$ de alimento)

T2: concentrado + aditivo con Saccharomyces cerevisiae, Bacillus subtilis y enzimas digestivas (proteasas, lipasas, amilasas y celulasas), $1 \mathrm{~kg} / \mathrm{t}$ de alimento

T3: concentrado $+15 \mathrm{~mL}$ del preparado microbiano ecuatoriano con bacterias lácticas, levaduras y enzimas (proteasas y amilasas) por kg de peso vivo

Los alimentos balanceados se formularon según los requerimientos nutricionales de la NRC (14) para cerdos en la etapa post-destete. Su composición se muestra en la Tabla II.

Tabla II. Composición de la dieta base utilizada en cerdos en post-destete

\begin{tabular}{|l|c|}
\hline Ingrediente & \% \\
\hline Maíz (\%) & 35,00 \\
\hline Polvillo de arroz (\%) & 5,00 \\
\hline Afrecho de trigo (\%) & 9,70 \\
\hline Harina de soya (\%) & 35,20 \\
\hline Harina de pescado (\%) & 2,00 \\
\hline DL-Metionina (\%) & 0,40 \\
\hline
\end{tabular}

\begin{tabular}{|l|c|}
\hline Ingrediente & \% \\
\hline L-Lisina (\%) & 0,40 \\
\hline Palmiste (\%) & 5,00 \\
\hline Melaza (\%) & 2,00 \\
\hline Aceite de palma (\%) & 2,90 \\
\hline Carbonato de calcio \%) & 0,50 \\
\hline Fosfato dicálcico (\%) & 1,10 \\
\hline Cloruro de sodio (\%) & 0,50 \\
\hline $\begin{array}{l}\text { Premezcla mineral y vitamínica } \\
\text { (\%) }\end{array}$ & 0,30 \\
\hline Aportes calculados (90\% materia seca) \\
\hline Proteína bruta (\%) & 22,49 \\
\hline Lisina (\%) & 1,22 \\
\hline Metionina + Cistina (\%) & 0,69 \\
\hline Triptófano (\%) & 0,21 \\
\hline Calcio (\%) & 0,71 \\
\hline Fósforo (\%) & 0,81 \\
\hline Fósforo disponible (\%) & 0,42 \\
\hline Extracto etéreo (\%) & 5,40 \\
\hline Fibra bruta (\%) & 4,84 \\
\hline Energía metabolizable (MJ/kg) & 13,60 \\
\hline
\end{tabular}

El antibiótico promotor de crecimiento y el probiótico con Saccharomyces cerevisiae, Bacillus subtilis y enzimas digestivas (proteasas, lipasas, amilasas y celulasas) se aplicaron según las instrucciones de los fabricantes (Phibro, EUA y Prince Agri Products, Inc., EUA, respectivamente). En el caso del preparado microbiano ecuatoriano, a base de suero de leche, se siguió la metodología descrita por Díaz et al. (10) para su elaboración y se caracterizó: $4 \times 10^{6}$ unidades formadoras de colonia (UFC) de bacterias lácticas y $1,5 \times 10^{5}$ UFC de levaduras por cada mililitro de producto; 9,62 $\mathrm{mg} / \mathrm{L}$ de enzimas proteasas; $7,38 \mathrm{mg} / \mathrm{L}$ de enzimas proteasas; $120 \mathrm{mg} / \mathrm{L}$ de ácido láctico y $\mathrm{pH}$ de 3,9. Este preparado se aplicó en el concentrado según T3 y su cantidad se ajustó semanalmente según el peso vivo de los animales en el corral. La mezcla 
de ambos se realizó en recipientes de plástico para garantizar la homogenización.

La respuesta de los animales al suministro de los tres aditivos en las dietas se determinó a través de los siguientes indicadores: peso vivo de los cerdos a los 70 días de edad; ganancia de peso de la etapa; ganancia de peso diaria; conversión de materia seca $(\mathrm{MS})$, proteína bruta $(\mathrm{PB})$ y energía metabolizable (EM); porcentajes de animales con diarreas y porcentaje de mortalidad. También se clasificaron las diarreas en producidas por Salmonella, Escherichia coli y trastornos digestivos. Para la detección de Salmonella, se sembraron diariamente muestras de heces de los animales con diarreas en agar Salmonella-Shigella (15). Las placas se incubaron $18-24 \mathrm{~h}$ a $35 \pm 2^{\circ} \mathrm{C}$ y se contaron las colonias negativas que son incoloras (lactosa negativa), las colonias positivas que son de color rosa-rojo (lactosa-positiva) y las colonias de centro negro productoras de $\mathrm{H}_{2} \mathrm{~S}$. Para la detección de $E$. coli se realizaron siembras en placas Petrifilm (16). Estas se incubaron durante $24-48 \mathrm{~h}$ a $42^{\circ} \mathrm{C}$ y se contaron las colonias positivas que aparecieron de color azul o rojo-azul. Las diarreas por trastornos digestivos se determinaron por diferencia entre el número total de muestras analizadas menos las que dieron positivos para Salmonella y E. coli.
Análisis estadístico. Los datos experimentales se procesaron con el paquete estadístico InfoStat (17). Se realizó análisis de varianza según diseño completamente aleatorizado y, en los casos necesarios, se aplicó la dócima de comparación de Duncan (18) para discriminar diferencias entre medias a $P<0,05$. Se aplicó un análisis de covariable para el peso vivo inicial con el objetivo de conocer si este influía en el comportamiento productivo de los animales. A las variables de conteo y a las expresadas en porcentaje (diarreas y número de muertes), se les realizó análisis de comparación de proporciones (chi cuadrado) con el paquete estadístico ComparPro (19).

\section{Resultados y discusión}

En la Tabla III se presentan los resultados del comportamiento productivo de los cerdos al suministrar los tres aditivos en la dieta. Hubo diferencias entre tratamientos $(\mathrm{P}<0,0001)$ para todas las variables en estudio, excepto el peso inicial que fue la variable concomitante. La menor respuesta productiva fue donde se aplicó el antibiótico promotor del crecimiento (APC). El peso vivo final, la ganancia de peso total y la ganancia de peso diaria fueron superiores con la adición del preparado microbiano, lo que estuvo relacionado con una mejor conversión de la materia seca, proteína bruta y energía metabolizable.

Tabla III. Comportamiento productivo de cerdos en el período post-destete con la inclusión de un preparado microbiano, probiótico comercial y virginiamicina (APC).

\begin{tabular}{|c|c|c|c|c|}
\hline \multirow[b]{2}{*}{ Indicador } & \multicolumn{3}{|c|}{ Tratamientos } & \multirow{2}{*}{$\begin{array}{l}\text { EE }( \pm) \\
\text { Signif. }\end{array}$} \\
\hline & APC & $\begin{array}{l}\text { Probiótico } \\
\text { comercial }\end{array}$ & $\begin{array}{l}\text { Preparado } \\
\text { microbiano }\end{array}$ & \\
\hline Peso inicial (kg) & 6,86 & 6,87 & 6,88 & $\begin{array}{c}0,03 \\
P=0,8862\end{array}$ \\
\hline Peso final (kg) & $22,49^{a}$ & $24,01^{b}$ & $25,85^{c}$ & $\begin{array}{c}0,13 \\
P<0,0001\end{array}$ \\
\hline Ganancia de peso total $(\mathrm{kg})$ & $15,64^{\mathrm{a}}$ & $17,14^{\mathrm{b}}$ & $18,97^{c}$ & $\begin{array}{c}0,14 \\
P<0,0001\end{array}$ \\
\hline Ganancia de peso diaria (g/d) & $372,50^{a}$ & $408,00^{b}$ & $451,75^{c}$ & $\begin{array}{c}3,23 \\
P<0,0001\end{array}$ \\
\hline $\begin{array}{l}\text { Conversión de } \mathrm{MS}(\mathrm{kg} / \mathrm{kg} \text { de } \\
\mathrm{PV})\end{array}$ & $1,85^{c}$ & $1,69^{b}$ & $1,52^{\mathrm{a}}$ & $\begin{array}{c}0,05 \\
P<0,0001\end{array}$ \\
\hline
\end{tabular}




\begin{tabular}{|l|c|c|c|c|}
\hline \multirow{2}{*}{ Indicador } & \multicolumn{3}{|c|}{ Tratamientos } & \multirow{2}{*}{$\begin{array}{c}\text { EE }( \pm) \\
\text { Signif. }\end{array}$} \\
\cline { 2 - 5 } & APC & $\begin{array}{c}\text { Probiótico } \\
\text { comercial }\end{array}$ & $\begin{array}{c}\text { Preparado } \\
\text { microbiano }\end{array}$ & $\begin{array}{c}3,77 \\
\text { Conversión de PB (g/kg de PV) }\end{array}$ \\
\cline { 1 - 4 } & $462,96^{\mathrm{c}}$ & $422,47^{\mathrm{b}}$ & $381,57^{\mathrm{a}}$ & $\mathrm{P}<0,0001$ \\
\hline $\begin{array}{l}\text { Conversión de EM (MJ/kg de } \\
\text { PV) }\end{array}$ & $27,90^{\mathrm{c}}$ & $25,44^{\mathrm{b}}$ & $22,99^{\mathrm{a}}$ & $\begin{array}{c}0,23 \\
\mathrm{P}<0,0001\end{array}$ \\
\hline
\end{tabular}

${ }^{a, b, c}$ valores con letras no comunes en la misma fila difieren a $\mathrm{P}<0,05$

La Figura 1 muestra el porcentaje de diarreas de los cerdos tratados con la virginiamicina, el probiótico comercial y el preparado microbiano. Se observa que en los grupos de animales donde se aplicaron ambos aditivos microbianos presentaron menor porcentaje respecto al APC, sin diferencias entre ellos. La mayor causa de las diarreas fueron los problemas digestivos, seguido por los proble- mas infecciosos causados por E. coli y Salmonella (Tabla IV). Estas últimas tuvieron poca frecuencia y su porcentaje no difirió entre los tres grupos de animales tratados. Los problemas digestivos si difirieron, observándose el menor valor para el preparado microbiano y el mayor para el antibiótico promotor del crecimiento.

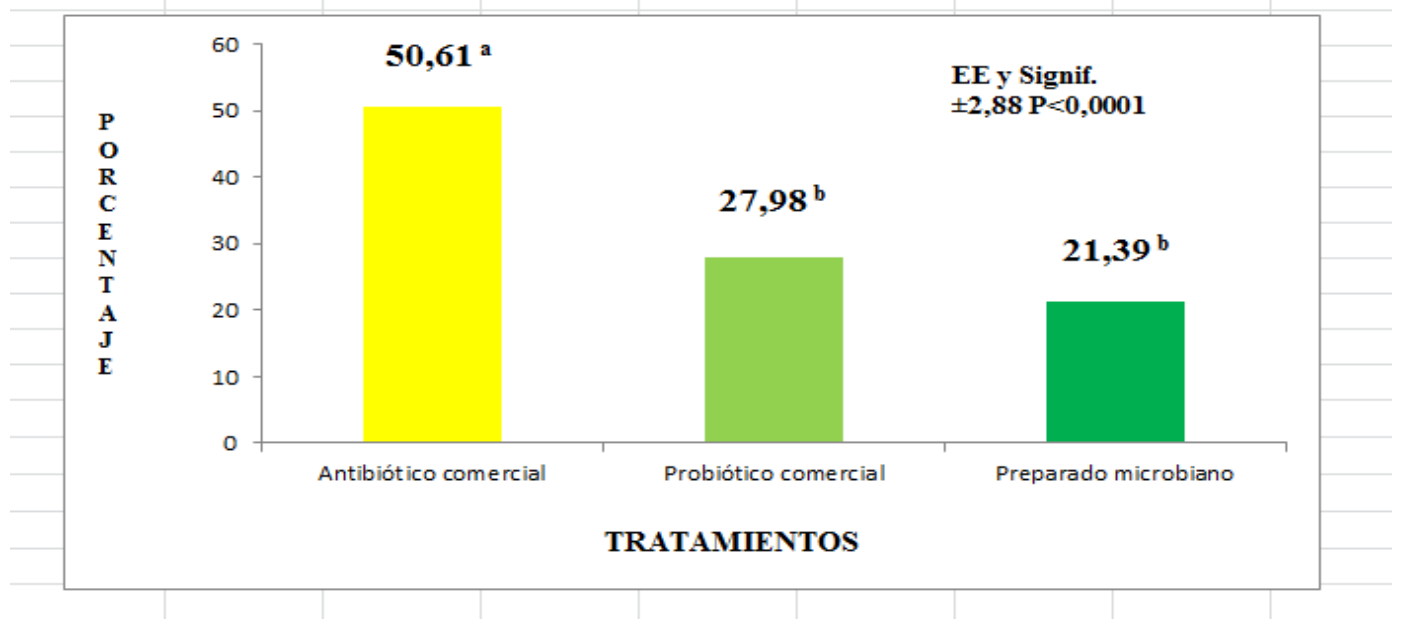

${ }^{a, b}$ valores con letras no comunes difieren a $\mathrm{P}<0,05$

Figura 1. Porcentaje de cerdos con diarreas al adicionar un antibiótico promotor del crecimiento (virginiamicina), un probiótico comercial y un preparado microbiano en la etapa de post destete. 
Tabla IV. Causas de diarreas en cerdos en la etapa de post-destete por efecto de la virginiamicina (APC), un probiótico comercial y un preparado microbiano.

\begin{tabular}{|c|c|c|c|c|c|}
\hline $\begin{array}{l}\text { Causas de } \\
\text { diarreas }\end{array}$ & Tratamientos & $\begin{array}{c}\text { Número de } \\
\text { animales con } \\
\text { diarrea }\end{array}$ & $\begin{array}{c}\text { \% de ani- } \\
\text { males con } \\
\text { diarrea }\end{array}$ & $\begin{array}{c}\text { Número total } \\
\text { de animales } \\
\text { con diarrea }\end{array}$ & $\begin{array}{l}\text { EE }( \pm) \\
\text { Signif. }\end{array}$ \\
\hline \multirow{3}{*}{ E. coli } & APC & 6 & 31,58 & \multirow{3}{*}{19} & \multirow{3}{*}{$\begin{array}{l}10,81 \\
\text { NS }\end{array}$} \\
\hline & $\begin{array}{l}\text { Probiótico } \\
\text { comercial }\end{array}$ & 9 & 47,37 & & \\
\hline & $\begin{array}{l}\text { Preparado } \\
\text { microbiano }\end{array}$ & 4 & 21,05 & & \\
\hline \multirow{3}{*}{$\begin{array}{l}\text { Salmonella } \\
\text { spp. }\end{array}$} & APC & 4 & 33,33 & \multirow{3}{*}{12} & \multirow{3}{*}{$\begin{array}{l}13,61 \\
\text { NS }\end{array}$} \\
\hline & $\begin{array}{l}\text { Probiótico } \\
\text { comercial }\end{array}$ & 5 & 41,67 & & \\
\hline & $\begin{array}{l}\text { Preparado } \\
\text { microbiano }\end{array}$ & 3 & 25,00 & & \\
\hline \multirow{3}{*}{$\begin{array}{l}\text { Problemas } \\
\text { digestivos }\end{array}$} & APC & 113 & $47,88^{\mathrm{a}}$ & \multirow{3}{*}{236} & \multirow{3}{*}{$\begin{array}{c}3,07 \\
P<0,0001\end{array}$} \\
\hline & $\begin{array}{l}\text { Probiótico } \\
\text { comercial } \\
\end{array}$ & 78 & $33,05^{b}$ & & \\
\hline & $\begin{array}{l}\text { Preparado } \\
\text { microbiano }\end{array}$ & 45 & $19,07^{c}$ & & \\
\hline
\end{tabular}

$\mathrm{a}, \mathrm{b}, \mathrm{c}$ valores con letras no comunes difieren a $\mathrm{P}<0,05$

El comportamiento de los indicadores anteriores al adicionar el preparado microbiano fue similar a los obtenidos por Flores et al. (11). Los resultados del presente estudio corroboran la actividad probiótica del preparado, quizás a través de una mejora de la digestión y absorción de nutrientes y de la salud intestinal de los animales, relacionadas, a su vez, con su efecto modulador del sistema inmune y la reducción o supresión de microorganismos potencialmente patógenos. Efectos que fueron discutidos por los autores en el estudio (11) y atribuidos a las levaduras y especies de Lactobacillus presentes en este preparado (10).

La eficacia de los aditivos microbianos, además de depender de la especie o cepa, puede variar al emplearse mezclas microbianas y según la combinación de éstas (20). Al parecer el comportamiento productivo y sanitario de los cerdos en el período post-destete del presente estudio estuvo relacionado con los géneros y especies de cada uno de los aditivos microbianos evaluados, que provocaron un efecto sinérgico diferente. Aspectos relacionados con este tema se abordan a continuación.

Las bacterias lácticas y levaduras poseen mecanismos de acción diferentes. Las primeras, de forma resumida, son capaces de adherirse al epitelio intestinal, colonizarlo y ejercer su actividad con efecto en los indicadores productivos (21). Las segundas, generalmente, tienen la capacidad de prevenir la adherencia y colonización de los microorganismos patógenos en las paredes del tracto gastrointestinal, preservando su función de barrera protectora e inhibiendo las funciones celulares de algunos patógenos como E. coli y Salmonella (22, 23). También debe mencionarse que las bacterias lácticas pueden disminuir los patógenos potenciales en el lumen intestinal debido a las sustancias antimicrobianas que producen (por ejemplo: bacteriocinas y ácidos orgánicos), y por ende, mejorar el comportamiento productivo de los cerdos (24). Las interacciones entre bacterias lácticas y levaduras no se conocen con exactitud, pero se plantea que el crecimiento de las primeras puede estimu- 
larse a través de la producción de dióxido de carbono, piruvato, propionato y succinato o por las vitaminas o aminoácidos producidos por las levaduras (25).

En el caso de Saccharomyces cerevisiae y Bacillus subtilis, presentes en el probiótico comercial, son microorganismos alóctonos del tracto gastrointestinal, por lo que se recomienda su suministro de forma diaria. Algunos autores plantean que estas especies no pueden colonizar el ecosistema microbiano intestinal pero pueden influir en su composición $(26,27)$. Acción que, fundamentalmente, se debe a la estimulación del sistema inmunológico y la actividad antimicrobiana, que influye en la disminución de los desórdenes intestinales (26). También, Milián (27) informó que $B$. subtilis puede competir por nutrientes y producir enzimas que favorecen los procesos de digestión y absorción.

Por otra parte, en el presente estudio la virginiamicina fue empleada como APC, esta pertenece al grupo de los estreptograminas e inhibe el crecimiento de bacterias Gram positivas, tanto aerobias como anaerobias, que a su vez puede incidir en la reducción de la producción de ácido láctico, amoníaco y ciertas aminas en el tracto gastrointestinal $(28,29,30)$. La disminución de la concentración intestinal de amoníaco y las aminas pueden reducir la tasa de paso de la digesta y, consecuentemente, aumentar la digestibilidad de nutrientes (vitaminas y minerales) en cerdos $(31,32)$, lo que pudo ocurrir en el actual estudio y debe corroborarse posteriormente.

Según Errecalde (3) la virginiamicina interfiere en la síntesis de peptidoglicanos, elementos esenciales de la constitución de la pared celular, y los defectos de ésta llevan a la lisis bacteriana solo cuando se encuentran en crecimiento activo. Por lo tanto, el amplio espectro de acción de este antibiótico puede afectar tanto a microorganismos potencialmente patógenos como benéficos, lo que hace que se altere el ecosistema microbiano y se deba restablecer la eubiosis intestinal. Asimismo, incide en la disminución de los metabolitos o sustancias tóxicas que producen estas poblaciones microbianas $y$, por consiguiente, modifica la morfología de las vellosidades y el peso de los órganos digestivos, lo que de forma general afecta la salud intestinal de los animales. Esto representa una desventaja frente a la utilización de otros aditivos zootécnicos como los probióticos, y que al parecer se manifestaron en el presente ensayo con cerdos en la etapa de post-destete.

En cuanto a la mortalidad, se puede observar en la figura 2 que no hubo diferencias entre los tratamientos, aunque se esperaba un mejor comportamiento de este indicador debido a los efectos benéficos producidos por los aditivos microbianos, que se comentaron con anterioridad. No obstante, al analizar biológicamente el resultado se puede observar que la mayor cantidad de muertes se produjo en el grupo donde se aplicó el antibiótico promotor del crecimiento.

\section{Conclusiones}

Los aditivos microbianos mejoran el comportamiento productivo y sanitario de cerdos en post-destete con respecto a la virginiamicina, y este efecto fue mayor con el preparado microbiano ecuatoriano. 


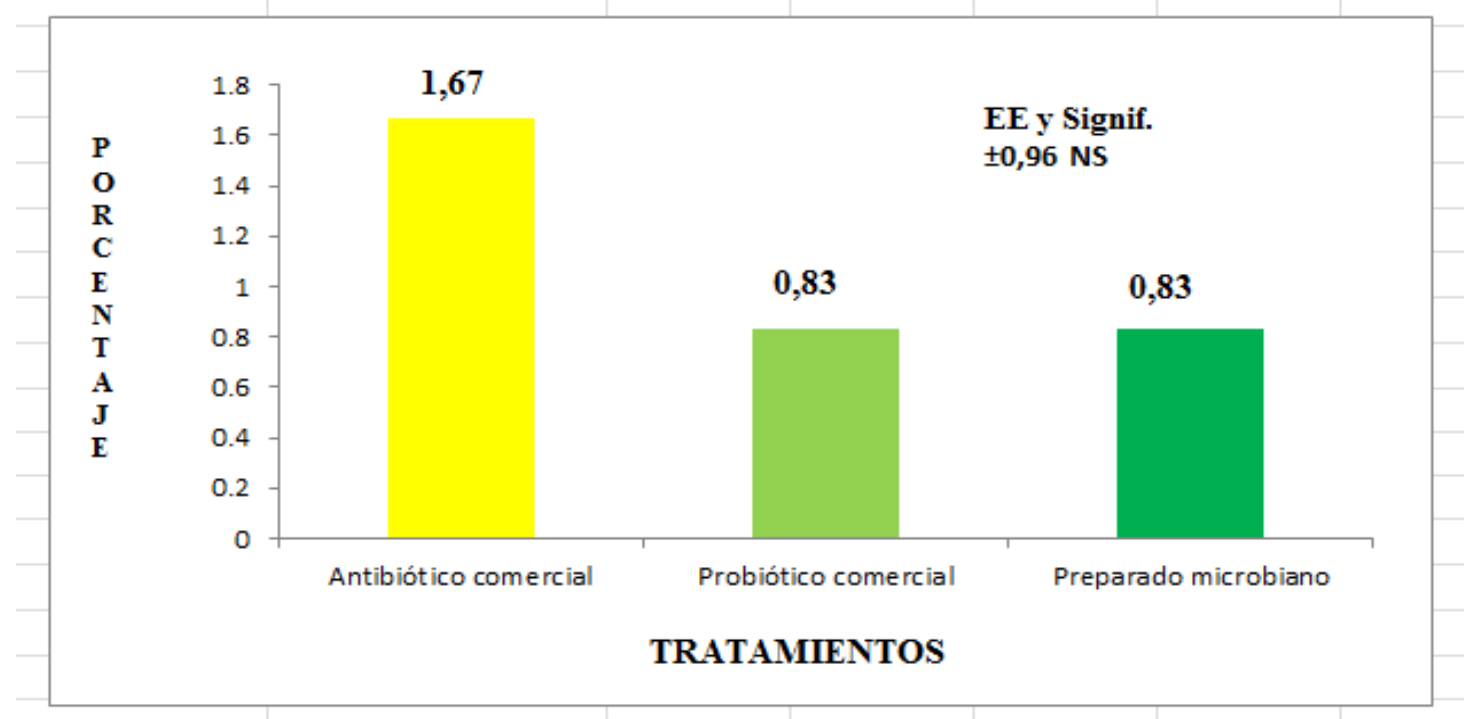

Figura 2. Mortalidad (\%) al adicionar un preparado microbiano, un antibiótico promotor del crecimiento y un probiótico comercial en la dieta de cerdos en el período de post-destete.

\section{Referencias}

(1) Davies P. Intensive Swine Production and Pork Safety. Foodborne Pathogens and disease. 2011; 8: 189-201. DOI: http://dx.doi.org/10.1089/ fpd.2010.0717.

(2) Cajarville C, Brambillasca S, Zumino P. Utilización de prebióticos en monogástricos: aspectos fisiológicos y productivos relacionados al uso de subproductos de agroindustrias y de pasturas en lechones. Revista Porcicultura Iberoamericana. 2011; 1: 1-11.

(3) Errecalde JO. Uso de antimicrobianos en animales de consumo. Incidencia del desarrollo de resistencias en salud pública. Producción y sanidad animal. Roma, Italia. 2004. 61 p.

(4) Maron D, Smith T, Nachman K. Restrictions on antimicrobial use in food animal production: an international regulatory and economic survey. Globalization and Health. 2013; 9: 1-11. DOI: http:// dx.doi.org/10.1186/1744-8603-9-48.

(5) Regulation EC No 1831/2003 of the European Parliament and Council of 22 September 2003 on additives for use in animal nutrition. Official J. Eur. Commun. 2003. L268, 29-43

(6) Food and Agriculture Organization of the United Nations/World Health Organization. Health and nutritional properties of probiotics in food including powder milk with live lactic acid bacteria. Report of a joint FAO/WHO expert consultation on evaluation of health and nutritional properties of probiotics in food including powder milk with live lactic acid bacteria in food. October 1-4 2001. Cordoba, Argentina. Disponible en: http://www. who.int/foodsafety/publications/fs_management/ en/probiotics.pdf.

(7) Gutiérrez L, Montoya O, Vélez J. Probióticos: Una alternativa de producción limpia y de reemplazo a los antibióticos promotores de crecimiento en la alimentación animal. Producción + limpia. 2013; 8:135.

(8) Jurado H, Pazmiño S, Benavidez V. Evaluación del efecto probiótico de Lactobacillus plantarum en la alimentación de lechones en fase de pre ceba como una alternativa del uso de antibióticos. Rev. Investigación Pecuaria. 2013; 2:55. 
(9) Quemac M. Evaluación de tres dosis de probiótico (Rhodopseudomonas spp, Lactobacillus spp., Saccharomyces spp.) en la alimentación para el engorde de cerdos. Tesis de Ingeniería, Universidad Estatal Politécnica del Carchi, Tulcán, Ecuador, 2014.

(10) Díaz B, Elías A, Valiño E. Consorcios microbianos con actividad acido-láctica promisoria aislados desde inoculantes bacterianos nativos para ensilajes. Rev. Cien. Agri. 2014; 11:17-25. DOI: http://dx.doi.org/10.19053/01228420.3484.

(11) Flores-Mancheno LG, García-Hernández Y, Proaño-Ortiz FB, Caicedo-Quinche WO. Evaluación de tres dosis de un preparado microbiano, obtenido en Ecuador, en la respuesta productiva y sanitaria de cerdos en posdestete. Rev. Cien. Agri. 2015; 12(2):59-70. DOI: http://dx.doi. org/10.19053/01228420.4392.

(12) Sanz Y, Collado MC, Dalmau J. Probióticos: criterios de calidad y orientaciones para el consumo. Acta Pediátrica Española. 2003; 61: 476-482.

(13) Boyle RJ, Robins-Browne RM, Tang MLK. Probiotic use in clinical practice: what are the risks?. American Journal of Clinical Nutrition. 2006; 83:1256-1264.

(14) Nutrient Requirement of Domestic Animals. Nutrient Requirements of Swine. National Academic Press.Washington, District of Columbia.

(15) Neogen. Salmonella Shigella Agar (7152). Acumedia, 2011.Disponible en: http:// www.neogen.com/Acumedia/pdf/ProdInfo/7152_PI.pdf.

(16) Petrifilm 3M. Placas para recuento de E. coli/ Coliform, 2010. Disponible en http:// multimedia. $3 \mathrm{~m} . c o m / \mathrm{mws} / \mathrm{media} / 701951 \mathrm{O} /$ product-instructions-3m-petrifilm-e-coli-coliform-count-plate. pdf .

(17) Di Rienzo J, Casanoves F, Balzarini M, Gonzalez L, Tablada M, Robledo C. Grupo InfoStat, FCA, Universidad Nacional de Córdoba, Argentina. InfoStat versión 1.0, 2012.
(18) Duncan DB. Multiple range and multiple $F$ tests. Biometrics. 1955, 11:1. DOI: http://dx.doi. org/10.2307/3001478.

(19) ComparPro versión 1. Font $\mathrm{H}$, Noda A, Torres V, Herrera M, Lizazo D, Sarduy L, Rodríguez L. Instituto de Ciencia Animal, Dpto. de Biomatemática, Cuba. 2007.

(20) Bomba A, Nemcová R, Mudroňová D, Guba P. The possibilities of potentiating the efficacy of probiotics. Trends Food Science \& Technology. 2002; 13: 121-126. DOI: http://dx.doi.org/10.1016/ S0924-2244(02)00129-2.

(21) García-Hernández Y, Pérez-Sánchez T, Boucourt R, Balcázar JL, Nicoli JR, Moreira-Silva J, Rodríguez Z, Fuertes $\mathrm{H}$, Nuñez O, Albelo N, Halaihel N. Isolation, characterization and evaluation of probiotic lactic acid bacteria for potential use in animal production. Research in Veterinary Science. 2016; 108:125-132. DOI: http://dx.doi. org/10.1016/j.rvsc.2016.08.009.

(22) Bach S, Talarek N, Andrieu T, Vierfond J, Mettey $\mathrm{Y}$. Isolation of drugs active against mammalian prions using a yeast-based screening assay. Nature Biotechnology. 2003; 21: 1075-1081. DOI: http:// dx.doi.org/10.1038/nbt855.

(23) Moslehi-Jenabian S, Lindegaard L, Jespersen L. Review: beneficial effects of probiotic and food borne yeasts on human health. Nutrients II. 2010; 449-473. DOI: http://dx.doi.org/10.3390/ nu2040449.

(24) Giang H, Viet T, Ogle B, Lindberg J. Effects of supplementation of probiotics on the performance, nutrient digestibility and fecal microflora in growing-finishing pigs. Asian-Aust. Journal of Animal Science. 2011; 24: 655-661.

(25) Álvarez-Martín P, Flórez AB, Hernández-Barranco A, Mayo B. Interaction between dairy yeasts and lactic acid bacteria strains during milk fermentation. Food Control. 2008; 19: 62-70. DOI: http:// dx.doi.org/10.1016/j.foodcont.2007.02.003. 
(26) Wang Y, Cho J, Chen Y, Yoo J, Huang Y, Kim $\mathrm{H}$, Kim I. The effect of probiotic BioPlus $2 \mathrm{~B}^{\circledR}$ on growth performance, dry matter and nitrogen digestibility and slurry noxious gas emission in growing pigs. Livestock Science. 2009; 120: 35-42. DOI: http://dx.doi.org/10.1016/j.livsci.2008.04.018.

(27) Milián G. Obtención de cultivos de Bacillus spp. y sus endosporas. Evaluación de su actividad probiótica en pollos (Gallus gallus domesticus). Tesis presentada para la opción de Doctor en Ciencias Veterinarias. Instituto de Ciencia Animal. La Habana, Cuba. 2009. 98 p.

(28) Vervaeke I, Decuypere J, Dierick N, Henderic$\mathrm{kx} \mathrm{H}$. Quantitative in vitro evaluation of the energy metabolism influenced by virginiamycin and spiramycin used as growth promoters in pig nutrition. Journal of Animal. Science. 1979; 49: 846-856. DOI: http://dx.doi.org/10.2527/jas1979.493846x.

(29) Ravindran V, Kornegay E, Webb K. Effects of fiber and virginiamycin on nutrient absorption, nu- trient retention and rate of passage in growing swine. Journal of Animal Science. 1984; 59: 400-408. DOI: http://dx.doi.org/10.2527/jas1984.592400x.

(30) Cromwell G. Antimicrobial and promicrobial agents. In Swine Nutrition. 2nd ed. A. J. Lewis and L. L. Southern, ed. CRC Press, Boca Raton, FL, 2001.

(31) Kass M, Van Soest P, Pond W, Lewis B, McDowell R. Utilization of dietary fiber from alfalfa by growing swine. I. Apparent digestibility of diet components in specific segments of the gastrointestinal tract. Journal of Animal Science. 1980; 50: 175-191. DOI: http://dx.doi.org/10.2527/ jas1980.501175x.

(32) Kim B, Lindemann M, Cromwell M, Balfagon A, Agudelo J. The correlation between passage rate of digesta and dry matter digestibility in various stages of swine. Livestock Science. 2007; 109: 81-84. DOI: http://dx.doi.org/10.1016/j.livsci.2007.01.082. 